Research Article

\title{
Low-Cycle Fatigue Properties of the X70 High-Frequency Electric-Resistant Welded Pipes
}

\author{
Peng Tian, ${ }^{1,2}$ Kai Xu, ${ }^{1}$ Guang-ping Lu, ${ }^{2}$ Gui-ying Qiao, ${ }^{1,3}$ and Fu-ren Xiao $\mathbb{D}^{1}$ \\ ${ }^{1}$ Key Lab of Metastable Materials Science and Technology, College of Materials Science and Engineering, Yanshan University, \\ Qinhuangdao 066004, China \\ ${ }^{2}$ Yangzhou Subsidiary, North China Petroleum Steel Pipe Co., Ltd., CNPC Bohai Equipment Manufacturing Co., Ltd., \\ Yangzhou 225128, China \\ ${ }^{3}$ School of Environmental and Chemical Engineering, Yanshan University, Qinhuangdao 066004, China
}

Correspondence should be addressed to Fu-ren Xiao; frxiao@ysu.edu.cn

Received 5 May 2018; Accepted 27 June 2018; Published 24 July 2018

Academic Editor: Marek Sroka

Copyright (c) 2018 Peng Tian et al. This is an open access article distributed under the Creative Commons Attribution License, which permits unrestricted use, distribution, and reproduction in any medium, provided the original work is properly cited.

The strength, toughness, corrosion, and fatigue resistance are the main requirements for evaluating the integrity of a pipeline. In this study, the tensile strength, impact toughness, and fatigue properties of the pipe body and weld joint of an X70 high-frequency electric-resistant welded (HFW) pipe were measured and the effects of microstructure and surface defects at weld joint on properties were discussed. Results show the appearance of a weakened zone at the weld joint of the X70 HFW pipe. Nevertheless, all mechanical properties, including strength and impact energy, were superior to the specified values of the API specifications for the X70 line pipe. The reduced strength, toughness, and resistance to $S-N$ fatigue of the weld joint caused the microstructural coarsening at the weld junction zone. However, for the specimens without surface finishing, the resistance to $S$ - $N$ fatigue for the weld joint was further reduced. This phenomenon was mainly attributed to the burring defects and microstructural coarsening at the heat-affected zone (HAZ). Therefore, to improve the quality of the X70 HFW pipe, refining the microstructure of weld joint and reducing the deburring defects by optimizing the postweld heat treatment (PWHT) and deburring processes should be firstly considered in the future research works.

\section{Introduction}

High-frequency electric-resistant welded (HFW) pipe presents many benefits, such as higher dimensional tolerance and lower prices, compared with seamless pipe and submerged-arc welded pipe. HFW pipes have been successfully applied for oil and gas transport $[1,2]$. However, the relatively low toughness of weld seam produced by HFW compared with other pipes severely limits the application of HFW in high-pressure gas transport. With the escalating gas consumption, the strength of pipeline steel should be improved to achieve high transmission efficiency and low operational costs. High-strength welded pipes necessitate high toughness to assure the operation security of highpressure gas transmission pipelines [3, 4]. In recent years, the strength and toughness of HFW pipes have been significantly improved with the application of new technology
[5-9]. High-strength HFW line pipe of API X70 and/or X80 grade is acceptable for use in extremely demanding and severe environments $[10,11]$.

However, in practical applications, fatigue is a main failure mode for gas transmission pipes because of the wave loading caused by daily fluctuations in pressure, such as working pressure, that stop and start during the operation $[12,13]$. Fatigue properties are some of the main requirements for evaluating the integrity of a pipeline [14]. Hence, the fatigue of pipeline steels and weld joints has been widely investigated [15-19]. However, previous studies mainly focused on the effect of microstructure on the fatigue crack propagation and the remaining life of steel and weld joint using standard fatigue test and/or numerical simulation $[18,19]$. Fatigue processes involve crack initiation, propagation, and final fracture [20]. The total life of a cyclic loaded component with a flaw depends on the propagation 
rate of the flaw from its original size to a critical size. This process induces the final fracture. The major part of the life is expended during crack propagation in the near-threshold $\Delta K$ region [21]. Therefore, the life of crack initiation and propagation at the flaw in the near-threshold $\Delta K$ region determines the total life of a cyclic loaded component. The fatigue crack is usually generated at the structural and mechanical defects on the surface in the component because repeated loading induces continuous accumulation of localized irreversible slip at the stress concentration sites. This phenomenon eventually triggers material separation, that is, crack formation.

In the modern pipeline design for oil and gas transmission, the submerged-arc welded pipes are prioritized over the HFW pipes. However, fatigue resistance frequently decreases at the weld joint of the pipes because of the strong stress concentration caused by the variation in chemical composition and microstructure between the weld metal and base metal, as well as the remaining weld reinforcement [22]. Hence, the weld joint of HFW pipes will have higher fatigue resistance because the weld joint does not have weld reinforcement. Meanwhile, the microstructure and mechanical properties can be improved by online postweld heat treatment (PWHT). In this study, these properties of an X70 HFW pipe were evaluated. The effects of the surface defects on the fatigue crack initiation were considered. The results will provide beneficial experimental data to improve the quality of the HFW pipe and expand its application.

\section{Experiment Procedures}

Hot-rolled API X70 microalloyed steel strips with $7.9 \mathrm{~mm}$ thickness were welded by HFW to fabricate a pipeline with $457 \mathrm{~mm}$ external diameter. The chemical composition of the X70 steel is provided in Table 1. The main manufacturing process of the X70 HFW pipes includes forming, HFW, deburring, online postweld heat treatment (PWHT), and so on. The welding speed of $15 \mathrm{~m} / \mathrm{min}$, extrusion of $8 \%$, and heat input of $520 \mathrm{~kW}$ were employed in HFW processes. The normalizing was performed on weld joint as online postweld heat treatment. The weld joint was heated to $930 \sim 940^{\circ} \mathrm{C}$ by online high-frequency induction heating, then air cooled to $400^{\circ} \mathrm{C}$, and subsequently water cooled to room temperature.

The weld seam and pipe body specimens were cut from the weld seam and prepared from $180^{\circ}$ along the circumference of the pipe in accordance with the API specifications for fabricating pipelines as schematically shown in Figure 1. Then, the plate fatigue specimens were machined. The size of the fatigue specimens is also shown in Figure 1. To assess the integrity of the X70 line pipe, two typical full-thickness plate fatigue specimens were used, that is, with or without surface finishing (the surface means as-rolled surface of the steel plate). This process was performed to reflect the actual fatigue life of the pipe and demonstrate the effect of the weld and PWHT, as well as the surface defects, on the fatigue life of the X70 HFW pipe.

The fatigue life tests were performed with an MTS servohydraulic universal testing machine. A stress ratio $\left(R=\sigma_{\min } / \sigma_{\max }\right)$ of 0.1 , a sinusoidal wave form, and a $10 \mathrm{~Hz}$ frequency were
TABLE 1: Chemical composition of the X70 pipeline steel.

\begin{tabular}{lcccccccc}
\hline $\mathrm{C}$ & $\mathrm{Si}$ & $\mathrm{Mn}$ & $\mathrm{P}$ & $\mathrm{S}$ & $\mathrm{Cr}$ & $\mathrm{Al}$ & $\mathrm{Ti}$ & $\mathrm{Nb}$ \\
\hline 0.07 & 0.24 & 1.55 & 0.011 & 0.002 & 0.15 & 0.028 & 0.014 & 0.051 \\
\hline
\end{tabular}

used for all tests. The maximum stress was applied as a controlled load at each of the seven stress levels. Each fatigue specimen was examined, until it fractured. The total fatigue cycles were calculated and served as the fatigue life measurement.

The microstructures and fractography were analyzed with an optical microscope and an S-3400N scanning electron microscope to understand the fatigue crack initiation, propagation, and final rupture.

\section{Results}

3.1. Microstructure and Mechanical Properties of the X70 HFW Pipe. The microstructure of the X70 pipeline steel is a typical acicular ferrite obtained by advanced thermalmechanical control process (Figure 2(a)). Thus, high strength and toughness were obtained (Table 2). The yield and tensile strengths of the pipe body (i.e., steel plate) were $525 \mathrm{MPa}$ and $620 \mathrm{MPa}$, respectively, and the average Charpy impact energy was approximately $192 \mathrm{~J}$. However, the acicular ferrite microstructure in the weld seam was disturbed by the HFW and PWHT. The microstructures of the weld junction and heat-affected zone (HAZ) changed to a mixture of ferrite and pearlite (Figures $2(\mathrm{c})$ and 2(d)). The ferrite grain size gradually coarsened from the base metal to the weld junction (Figures 2(b)-2(d)), and the coarsest microstructure appeared at the weld junction (Figure 2(d)). The coarse microstructure resulted in reduced mechanical properties of weld seam (Table 2). The tensile strength of the weld seam approximately decreased by over $10 \mathrm{MPa}$ than that of the pipe body, and the Charpy impact energy was reduced to $130 \mathrm{~J}$. Nevertheless, the values of the mechanical properties for the X70 HFW pipe remained superior to the specified value of the API specifications for the X70 line pipe.

3.2. Stress-Number of Fatigue Cycle (S-N) Curves of the X70 HFW Pipe. The pipeline pipes, except the surface coating, do not require any other surface finishing, when they are applied in transmission pipelines. Hence, the fatigue test specimens without surface finishing could better reflect the fatigue properties of a pipeline. The stress $(S)$-number of fatigue cycle $(N)$ curves obtained from the load control fatigue tests for the pipe body and weld joint without surface finishing were first determined (Figure 3). A considerable decrease (by over $50 \mathrm{MPa}$ ) in the resistance to $S-N$ fatigue of the welded joint was observed than that of the pipe body. Kim et al. [23] suggested that the resistance to $S-N$ fatigue was largely determined by the yield strength or arguably by the tensile strength of metals. However, the tensile strength of the welded joint was lower by approximately $10 \mathrm{MPa}$ than that of the pipe body. This result indicates the presence of other factors that affect the resistance to $S-N$ fatigue. 


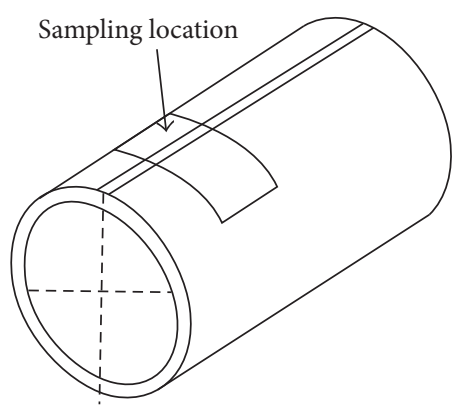

(a)

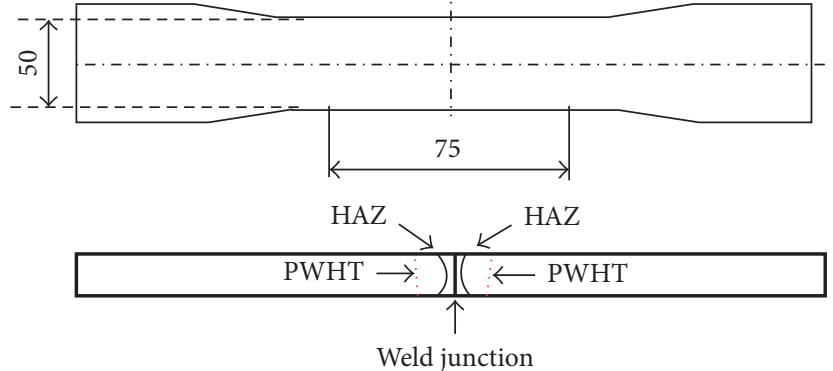

(b)

Figure 1: (a) Schematic illustration of the locations of cut and preparation of the test specimens. (b) The critical dimensions of the fatigue test specimens (all dimensions are in millimeter).
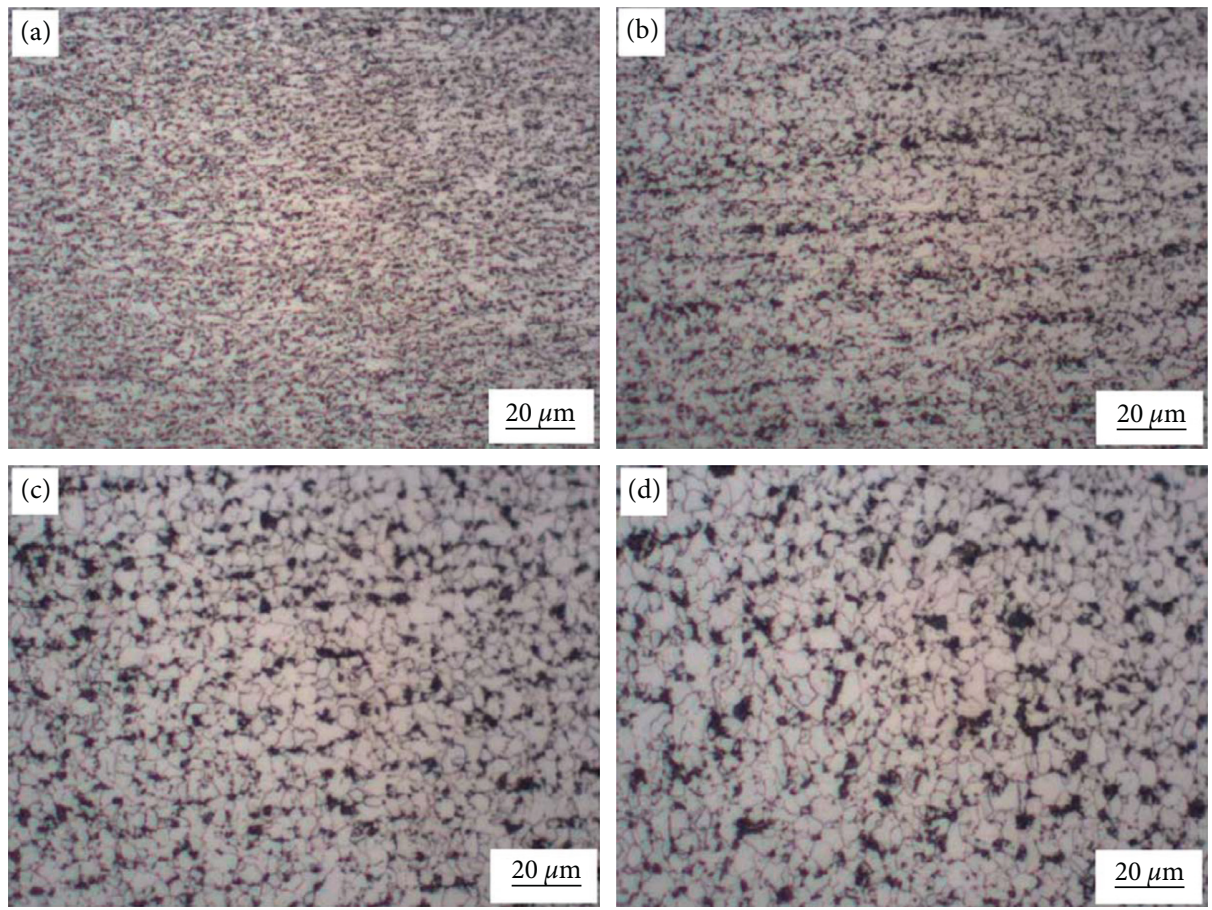

Figure 2: Optical microstructure of the weld joint: (a) base metal, (b) heat-affected zone (HAZ) close to the base metal, (c) HAZ close to the weld junction, and (d) weld junction.

Athanasios et al. [24] reported that fatigue cracks generally originated on the surface of the sample, and this phenomenon greatly affected the fatigue life. To estimate the effect of surface breaking irregularities, the $S-N$ curves of the pipe body and weld joint with surface finishing were also measured (Figure 3). The results show that the surface finishing strongly improved the fatigue performance of the HFW pipe. The resistance to $S-N$ fatigue of the welded joint and pipe body was higher than that of the specimens without surface finishing. The resistance to $S$ $N$ fatigue of the welded joints was still lower than that of the pipe bodies, with an approximate reduction of $20 \mathrm{MPa}$. Nevertheless, the resistance to $S-N$ fatigue of the welded joints was higher than that of the pipe bodies without surface finishing.

3.3. Macrofracture Analysis. The typical macrofractography of the specimens after fatigue fracture at same stress is shown in Figure 4. In all cases, the fracture surface contained two clear cut sections, namely, the flat rupture section and ductile rupture section.

"The flat rupture section" corresponds to the typical of fatigue failure. Within this section, the accumulation of microstructure defects and mechanical property defects in materials may have been caused by cyclic loading [23-25]. Nucleation and propagation of microdefects occurred; that is, a fatigue microcrack was initiated at the accumulated defects. Then, microcracks propagated perpendicular to the cyclic loading and left crack-like tear on the surface of fatigue damage [26]. Nucleation of fatigue failure processes always begin from the surface [27]. Therefore, fatigue crack initiation is sensitive to the micro- and/or macrodefects of the microstructure and mechanical properties near the surface of specimens [26,27]. Only one of the fatigue cracks was initiated on the fracture surface of the pipe body specimens with surface finishing (Figure 4(a)). By contrast, more than 
TABLE 2: Mechanical properties of the X70 HFW pipes.

\begin{tabular}{|c|c|c|c|c|c|c|}
\hline & \multicolumn{2}{|c|}{ Yield strength (MPa) } & \multicolumn{2}{|c|}{ Tensile strength $(\mathrm{MPa})$} & \multicolumn{2}{|c|}{ Impact energy $(\mathrm{J})$} \\
\hline & Tested value & Specification & Tested value & Specification & Tested value & Specification \\
\hline Pipe body & 525 & $481-621$ & 620 & $565-758$ & 209 & 120 \\
\hline Weld seam & \multicolumn{2}{|c|}{-} & 605 & $565-758$ & $\begin{array}{c}130 \text { (weld junction) } \\
172 \text { (HAZ) }\end{array}$ & 60 \\
\hline
\end{tabular}

one fatigue crack was initiated on the surface of the pipe body specimens without surface finishing (Figure 4(b)) because more surface defects may have existed on the surface of the hot-rolled steel plate. The weld joint apparently followed similar rules. Only one of the fatigue cracks initiated at the weld seam was observed on the fracture surface of the weld joint with surface finishing (Figure 4(c)). However, for the weld joint without surface finishing, fatigue crack was apparently generated along the weld seam (Figure 5(d)). The appearance of the fatigue crack initiation may be related to the effect of deburring on the cross-sectional geometry and surface of the weld joint.

The ductile rupture section is considered a quasistatic fracture when the bearing capacity of specimens is less than the maximum cyclic loading because fatigue crack propagation reduces the loading area [26]. In this section, larger ductile deformation was observed, and the fracture was similar to static tensile. However, variations in the deformation of the specimens were noted between the pipe body and weld joint. The deformational manifestations at the macro level were mostly pronounced in the pipe body than in the weld joint. This phenomenon indicates that the weld joint ruptured at the weld seam because the weld seam may have low plasticity [28].

3.4. Microfracture Analysis. The macrofractography shows that the fatigue failure processes included fatigue crack initiation, propagation, and final rupture (Figure 4). In these processes, the fatigue crack initiation and propagation are the most important processes that determine fatigue endurance [20]. Therefore, the microfractures caused by crack initiation and propagation were analyzed in detail by SEM (Figures 5 and 6).

3.4.1. Fatigue Crack Initial States. Figure 5 shows the fractography of the initial crack side of all specimens. In the pipe body or weld joint specimens with surface finishing, the fatigue cracks were generated at a small dot scope on the surface and grew inward in radial directions, which were clearly displayed by the river pattern (Figures $5(\mathrm{a})$ and $5(\mathrm{c})$ ). At the initial crack zone, fine transgranular tear facets were observed on the fracture surface of each specimen in the pipe body or weld joint with surface finishing. No notable difference was observed in the morphology of the fracture mode (Figures 5(b) and 5(d)). The change in failure mechanism from ductile tear manner was responsible for the increased fatigue resistance of pipe body to the weld joint [25].

However, several differences were found between the pipe body and weld joint without surface finishing. For example,

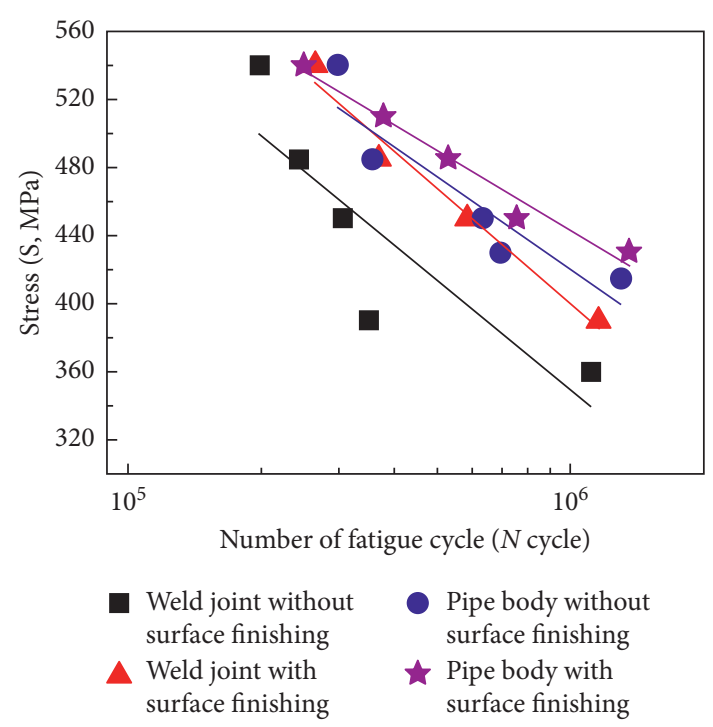

FIGURE 3: Stress-number of fatigue cycle curves evaluated at $R=0.1$, $10 \mathrm{~Hz}$, and room temperature for the pipe body and the welded joint with and without surface finishing.

more than one fatigue crack nuclei were generated at a surface defect of the pipe body specimen without surface finishing and grew to a large fatigue crack (Figure 5(e)). The microfractography showed the fine transgranular tear facets on the fracture surface (Figure 5(f)). This result is similar to the pipe body specimen with surface finishing (Figure 5(b)).

In addition, the fatigue crack of specimens of weld joint was generated with a long line-like crack along the weld seam (Figures 5(g) and 5(h)), and a linear defect was observed on the surface along weld seam (Figure 5(h)). Meanwhile, coarse transgranular cleavage facets compared with the other specimens were observed on the fracture surface (Figure 5(h)). The notable variations in the brittle fracture mechanism may be relative to the "burring" surface defects and coarsening microstructure of the weld seam.

3.4.2. Fatigue Crack Propagation States. Figure 6 shows the microfracture surface at the crack propagation section of the pipe body and weld joint specimens with and without surface finishing. The microfracture surfaces were uniform and contained transgranular cleavage facets and rough relief [26]. Simultaneously, fatigue striations were found on several transgranular cleavage facets and/or on the steps of the roughness reliefs. In addition, certain secondary cracks caused by microtear appeared were found on the surface. However, the facet size on the fracture surface of the pipe body was smaller than the pipe body, and several dot-like 

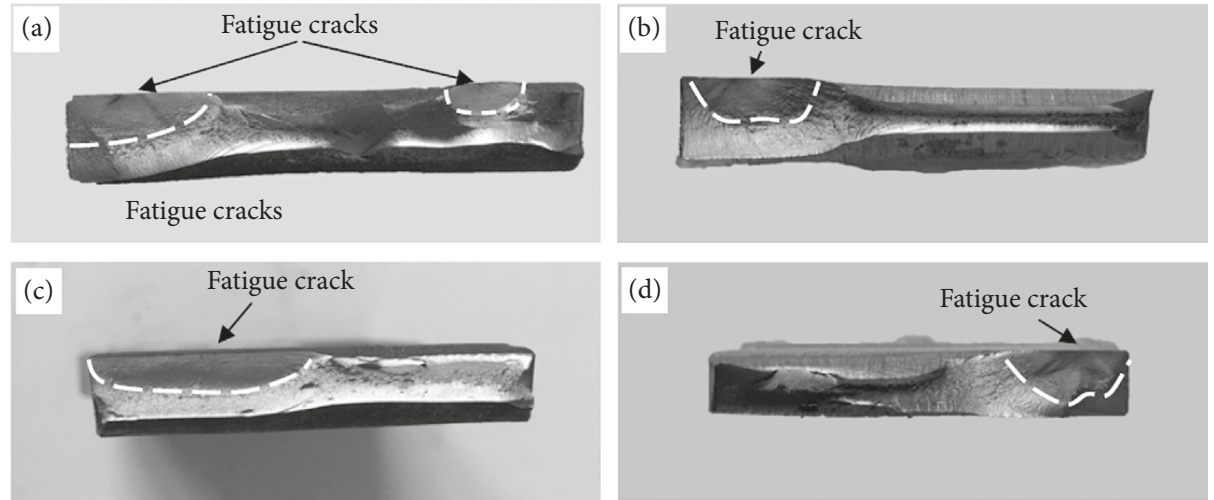

Figure 4: Typical macrofractures of the pipe body (a) without surface finishing and (b) with surface finishing and those of the weld joint (c) without surface finishing and (d) with surface finishing.

reliefs were observed in the facets and at the side of secondary cracks. The specific different rupture characteristics presented between the pipe body and the weld joint may be related to the variation in the microstructure at the fracture zone. The microstructure of the pipe body was refined acicular ferrite, whereas the microstructure of weld joint was coarsened polygonal ferrite (Figure 2).

\subsection{Microstructure of the Fracture Section of the Weld Joints.} The fractographic results show that the change in fracture manner between the pipe body and the weld joint may be related to the difference in microstructures (Figures 5 and 6). Thus, the fatigue fracture of the weld joint should be the weld seam and HAZ. Figure 7 shows the microstructure near the fracture surface of weld joints with and without surface finishing, as well as the microstructure of the weld seam and HAZ. Figure 7(a) shows that the microstructure near the fracture of weld joint with surface finishing was coarsened polygonal ferrite and pearlite. By contrast, the microstructure near the fracture of weld joint without surface finishing was polygonal ferrite and pearlite with a banded microstructural characteristic (Figure $7(\mathrm{~b})$ ). Figure 2 shows that the zone with coarse microstructure of polygonal ferrite and pearlite corresponded to the weld junction, whereas the zone with banded polygonal ferrite and pearlite corresponded to the HAZ. The results were further confirmed by the scanning electron micrographs in Figures 7(c) and 7(d).

\section{Discussion}

The X70 HFW pipe had high strength, impact toughness (Table 2), and fatigue resistance (Figure 3). Lower mechanical properties appeared in the weld joint. The tensile strength of the weld joint decreased by approximately $15 \mathrm{MPa}$ than that of the pipe body, and the impact energy was reduced from $209 \mathrm{~J}$ for the pipe body to $130 \mathrm{~J}$ for the weld seam. Meanwhile, fatigue resistance also decreased. The microstructural results showed that the coarsened polygonal ferrite and pearlite were obtained in the weld seam, whereas no obvious oxide and other inclusions were observed (Figure 2). The fatigue fractography shows that the fatigue crack was initiated at a line defect on the surface of weld joint without surface finishing, which resulted in reduced fatigue resistance (Figure 4). However, the fatigue crack initiation side in the HAZ was confirmed by the microstructural observation of fracture cross section (Figure 7). All results suggest that the weld seam as the weakest location for the X70 HFW pipe was not caused by oxide and other inclusions, which were assumed to be the primary reason for reduced mechanical properties of the weld seam [6]. The law of cause and effect should be considered in searching for a cause to improve the mechanical properties of HFW pipes.

The key processes that affect the microstructure and mechanical properties of a weld seam mainly included pipe forming, welding, deburring, and online PWHT. The key processes are illustrated in Figure 8. During welding, the dual edge of the steel plate from the upstream side of the welding spot was first heated by joule heat. Then, the melting metal was generated at the approximate welding abutting point of the dual edge of the plate. Finally, the melted metal was pressed together by squeezing (Figure $8(a)$ ), whereby a metallurgical bond formed with the extruded melt metal including oxide inclusions, and the formed weld seam is illustrated in Figure 8(b). Many investigations and betriebspraxis studies $[1,2,10,11]$ have demonstrated that high weld quality could be guaranteed by optimizing the welding process parameters, such as the electrical power input, welding speed, plate thickness, apex angle, and squeezing force. Therefore, high weld quality of the X70 pipe was obtained. For example, no oxide inclusions were observed in the microstructure. Meanwhile, the mechanical properties at the weld joint decreased, and the key factors that affect the weld quality were discussed.

Fatigue, as the most important parameter for integrity evaluation, can better evaluate the weld quality of HFW pipes because fatigue crack initiation and propagation are more sensitive to the structure and properties of metals [25]. Oxides and other inclusions at the weld junction could facilitate fatigue crack initiation and propagation and decrease fatigue resistance. Figure 3 shows that the fatigue resistance of the weld joint with surface finishing was lower than that of the pipe body, while the reduction was only observed near the tensile strength. Jung et al. [26] suggested 

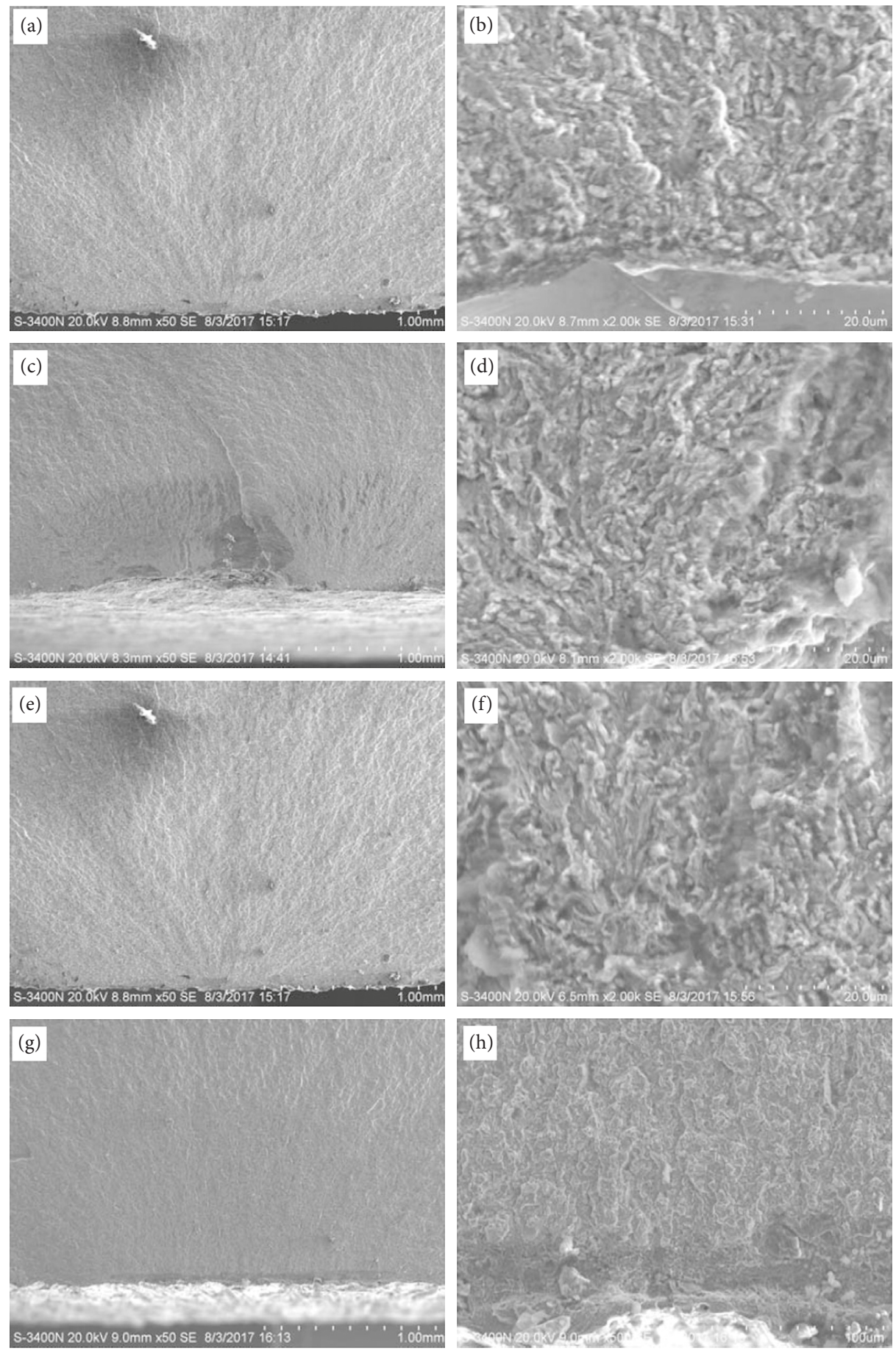

Figure 5: Typical fractures at the crack initiation zone of $(a-d)$ the pipe bodies and (e-h) weld joints (a, b, e, f) with and (c, d, g, h) without surface finishing.

that fatigue resistance was largely determined by the yield strength or arguably by the tensile strength. Meanwhile, no oxide inclusions were observed in the microstructure (Figure 2) and fracture surface (Figure 4). Thus, X70 HFW pipe exhibited improved weld quality.

However, the weld junction and its HAZ formed by joule heating and squeezing were disturbed and deteriorated because of the high temperature. Thus, PWHT processes play an important role in improving the microstructure and mechanical properties of the weld junction and its HAZ [29]. In this study, online normalization was performed as PWHT processes for the X70 pipe. The PWHT process parameters were as follows: heating temperature, $950^{\circ} \mathrm{C}$; and cooling rate from $950^{\circ} \mathrm{C}$ to $500^{\circ} \mathrm{C}, 3-5^{\circ} \mathrm{Cs}^{-1}$. At the lower cooling rate, the weld seam displayed mixed microstructure of coarsened polygonal ferrite and pearlite (Figure 2). This characteristic caused the lower strength and toughness of weld joint than those of the pipe body with fine acicular ferrite. We showed 

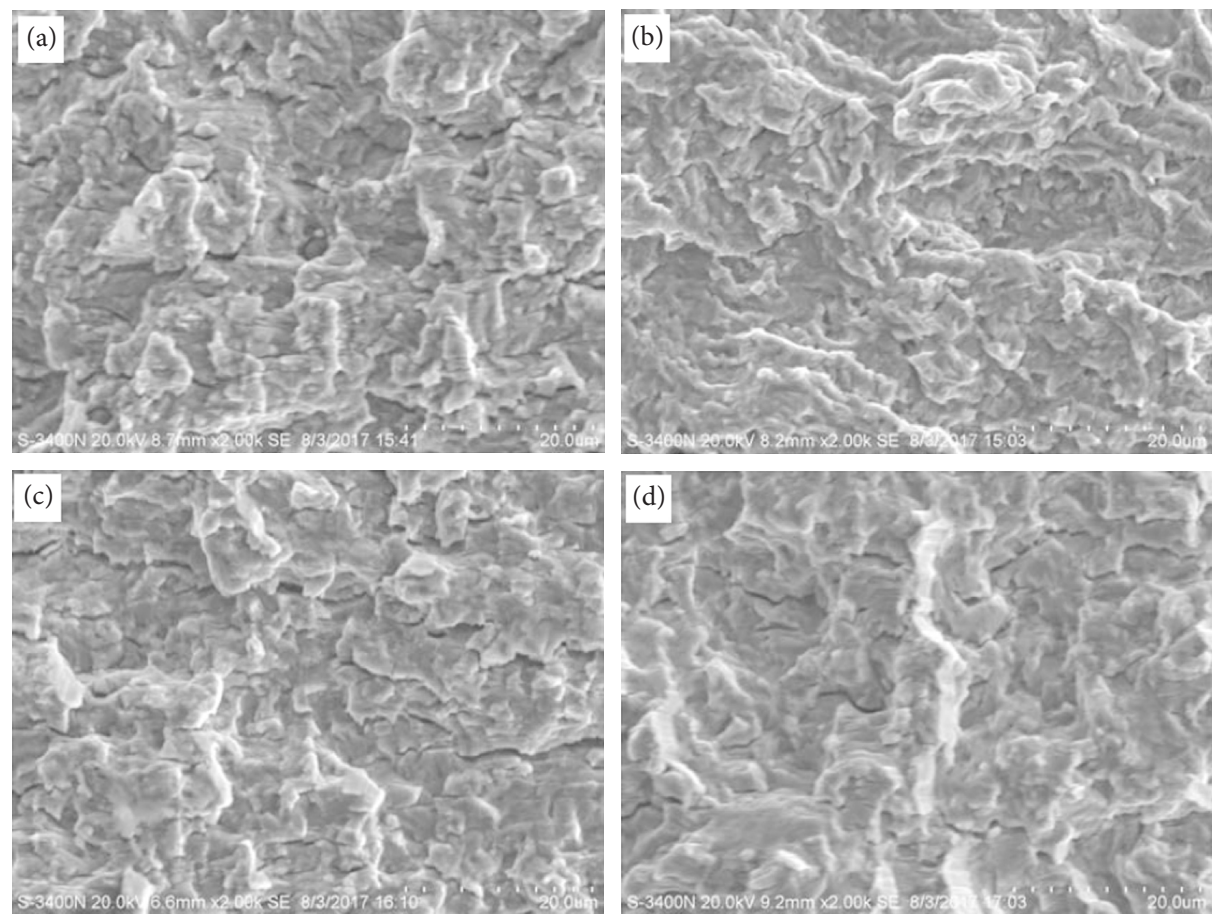

Figure 6: Typical fractures at the crack propagation zone of (a, b) the pipe bodies and (c, d) weld joints (a, c) with and (b, d) without surface finishing.
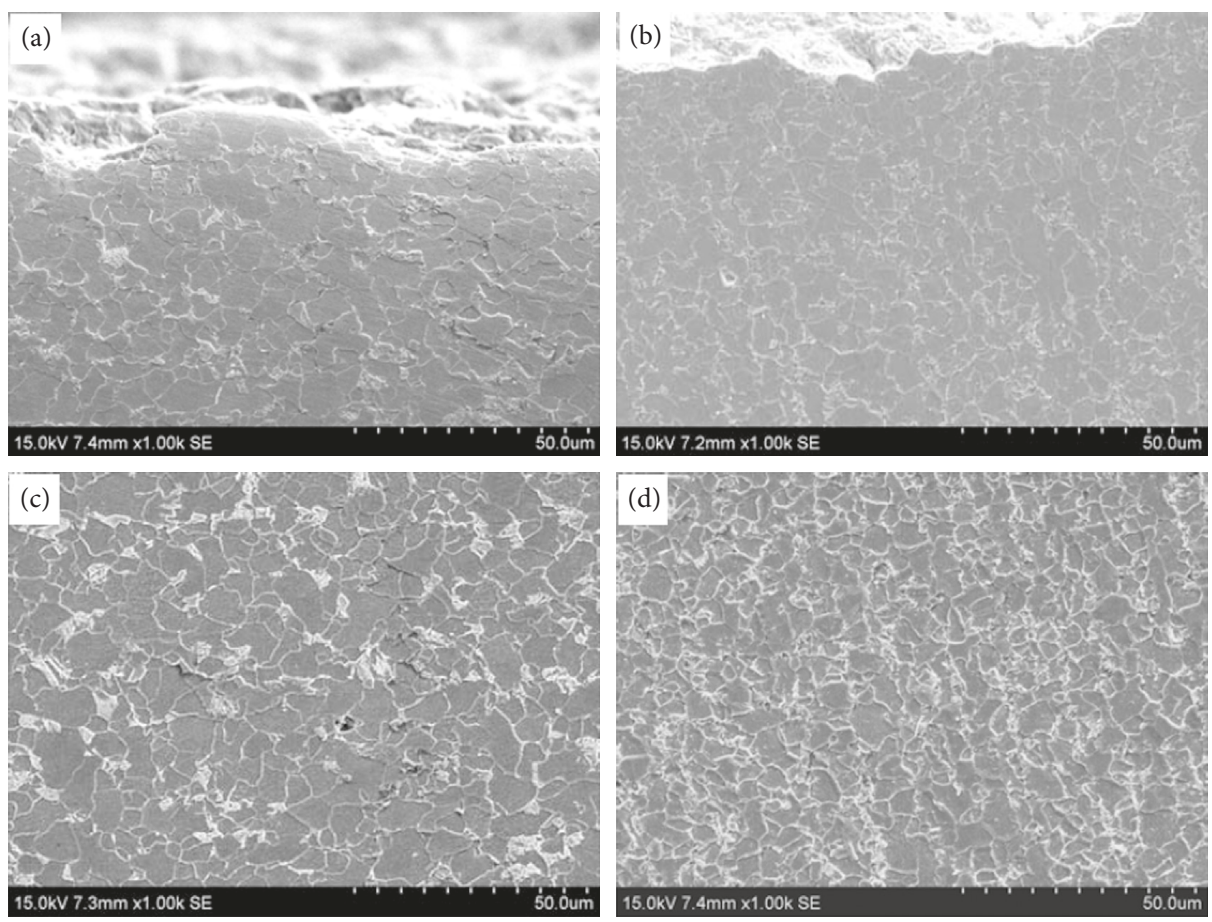

Figure 7: Microstructures of the fracture section of the weld joint specimens (a) with and (b) without surface finishing, and the microstructures of (c) weld junction and (d) HAZ.

in our previous study [30] that the heat treatment process parameters, such as the austenitizing temperature and cooling rate, especially the latter, greatly affect the microstructure and mechanical properties. From this point, increasing the cooling rate would help improve the microstructure and mechanical properties of the weld seam. This process needs further investigation.

In addition, the pipe body or weld joint with surface finishing showed higher resistance to $S-N$ fatigue than those without surface finishing. Meanwhile, the decreasing degrees 


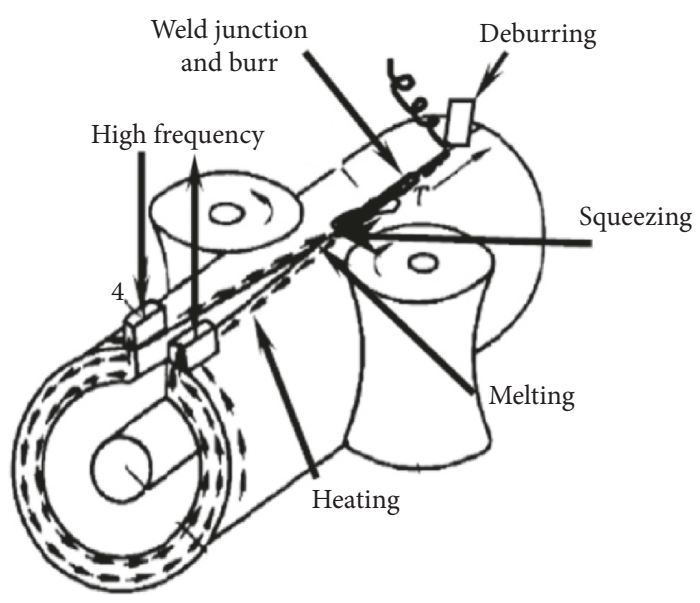

(a)

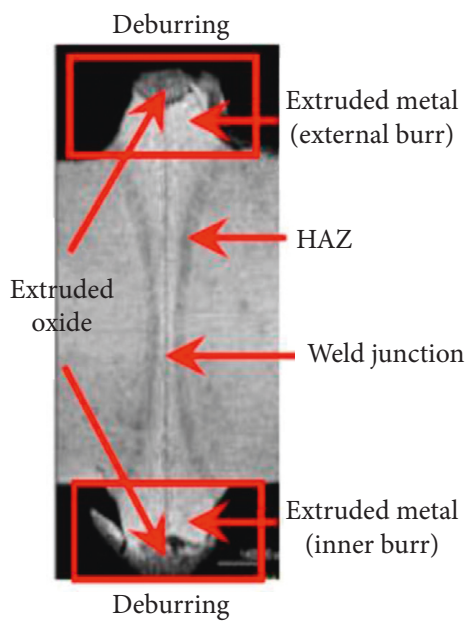

(b)

FIgURE 8: Schematic illustrates (a) the welding processes and (b) the structure of weld joint.

of the resistance to $S-N$ fatigue for the weld joint were higher than those of the pipe body (Figure 3). Fatigue is always generated on the surface [23-26, 31, 32], which implies that fatigue crack initiation is more sensitive to the surface defects [32]. Thus, fatigue cracks of all specimens were generated on the surface, and more nuclei of fatigue cracks appeared on the surface of the pipe body specimens without surface finishing (Figure 4). Moreover, several small oxidized pit defects on the as-rolled plate surface facilitated the fatigue crack initiation (Figure 5), which resulted in a small reduction in the resistance to $S-N$ fatigue for pipe body without surface finishing (Figure 3). Conversely, a bigger reduction in the resistance to $S-N$ fatigue occurred in the weld joint specimens without surface finishing (Figure 3). Meanwhile, the fatigue crack nucleus became line-like along the weld seam (Figures 4 and 5). Figure 8(b) shows that a raised upset of melted metal formed at the weld seam by squeezing. This formation was named "burr," and the burr should be removed online by deburring machines. In this case, line-like defects possibly formed along the side of the burr. The orientation for the long surface defect has a great effect on the fatigue crack initiation and propagation $[33,34]$. Given that the long surface defect is perpendicular to the principal stress direction, the fatigue cracks will be easily generated at the sharp corners of the long surface defect and quickly propagated in the depth direction [34]. The results of the microstructural observation of the fracture section verified that the fatigue crack of the weld joint specimens without surface finishing was generated at the HAZ (Figure 6). This result was consistent with the burring in Figure 7. Hence, the trails and defects caused by deburring in HAZ were the main reasons for the reduced resistance to $S-N$ fatigue of the weld joint without surface finishing. Nevertheless, compared with our previous work on the X80 submerged-arc welded pipe [22], the decreasing degrees of resistance to $S-N$ fatigue between the weld joint and pipe body were comparable, which were approximately $80 \mathrm{MPa}$ for the X70 HFW pipe and $100 \mathrm{MPa}$ for the X80 submerged-arc welded pipe [22]. The results indicate that the HFW pipes and submerged-arc welded pipe had similar weld qualities.
Hence, the X70 HFW pipe exhibited good mechanical properties. All mechanical properties were superior to the specified API specifications for the X70 line pipe. Although a weakened zone appeared at the weld joint, the resistance to $S-N$ fatigue of the pipe body and weld joint specimens with surface finishing showed that the weld joint had high weld quality. The reduced strength, toughness, and fatigue resistance of the weld joint could be ascribed to the microstructural coarsening at the weld junction zone. This phenomenon was more mainly related to the PWHT processes. Moreover, the resistance to $S-N$ fatigue of the weld joint specimens without surface finishing was further reduced than the specimens with surface finishing. The reduced resistances were mainly attributed to deburring defects and microstructure coarsening in HAZ. Therefore, future key works to improve the X70 HFW pipe quality should focus on refining the microstructure and improving the surface quality of the weld junction and HAZ.

\section{Conclusions}

In this work, the mechanical properties of the X70 HFW pipe were comprehensively assessed. The following conclusions were drawn:

(1) High weld quality can be achieved in the HFW pipe. Although a weakened zone appeared at the weld joint of the X70 HFW pipe, all mechanical properties were superior to the API specifications for the X70 line pipe.

(2) The resistance to $S-N$ fatigue of the weld joint specimens with surface finishing decreased by approximately $20 \mathrm{MPa}$ compared with that of the pipe body. This result is similar to the decrease in the tensile strength between the pipe body and the weld joint. The resistance to $S-N$ fatigue was largely determined by the tensile strength of the materials.

(3) The reductions in the strength, toughness, and fatigue resistance of the weld joint were mainly related to the microstructural coarsening at the weld 
junction zone. These coarsened microstructures could be improved by optimizing the parameters of PWHT in the future.

(4) The surface defects, particularly the burring defects, could become the fatigue crack-initiated nuclei and accelerate fatigue crack initiation and propagation. Furthermore, the X70 HFW pipe showed decreased resistance to $S$ - $N$ fatigue. Optimizing the PWHT and removing the burr processes are key factors to improve the $\mathrm{X} 70 \mathrm{HFW}$ pipe quality in future studies.

\section{Data Availability}

The data used to support the findings of this study are available from the corresponding author upon request.

\section{Conflicts of Interest}

The authors declare that they have no conflicts of interest.

\section{Acknowledgments}

This work was supported by the National Natural Science Foundation of China (Grant no. 51671164) and the Natural Science Foundation-Steel and Iron Foundation of Hebei Province (Grant no. E2015203234).

\section{References}

[1] T. Okabe, K. Yasuda, and K. Nakata, "Dynamic observations of welding phenomena and finite element analysis in highfrequency electric resistance welding," Welding International, vol. 30 , no. 11, pp. 835-845, 2016.

[2] G. Khalaj, H. Pouraliakbar, M. R. Jandaghi, and A. Gholami, "Microalloyed steel welds by HF-ERW technique: novel PWHT cycles, microstructure evolution and mechanical properties enhancement," International Journal of Pressure Vessels and Piping, vol. 152, pp. 15-26, 2017.

[3] P. S. Zhou, B. Wang, L. Wang, Y. W. Hu, and L. Zhou, "Effect of welding heat input on grain boundary evolution and toughness properties in CGHAZ of X90 pipeline steel," Materials Science and Engineering A, vol. 722, pp. 112-121, 2018.

[4] L. H. Qi, Z. L. Jin, J. M. Zhang, Y. L. Wang, M. J. Hu, and Z. C. Wang, "Influence factors of X80 pipeline steel girth welding with self-shielded flux-cored wire," Materials Science and Technology, vol. 33, no. 5, pp. 592-601, 2017.

[5] D. Kim, T. Kim, Y. W. Park, K. Sung, M. Kang, and C. Kim, "Estimation of weld quality in high-frequency electric resistance welding with image processing," Welding Journal, vol. 86, pp. 71s-79s, 2007.

[6] T. Fukami, N. Mizuhashi, N. Hasegawa et al., "Development of the new welding control method for HF-ERW pipesadvanced welding process of HF-ERW 1," in Proceedings of the Biennial International Pipeline Conference, vol. 3, pp. 229-236, Calgary, Canada, September 2012.

[7] N. Hasegawa, H. Hamatani, N. Mizuhashi et al., "Development of a new optical monitoring system of welding conditions for producing HF-ERW line pipes with high weld seam toughness-advanced welding process of HF-ERW 2," in Proceedings of the Biennial International Pipeline Conference, vol. 3, pp. 237-245, Calgary, Canada, September 2012.
[8] H. Hamatani, F. Watanabe, N. Mizuhashi et al., "Development of laminar plasma shielded HF-ERW process-advanced welding process of HF-ERW 3," in Proceedings of the Biennial International Pipeline Conference, vol. 3, pp. 211-218, Calgary, Canada, September 2012.

[9] P. Simion, V. Dia, B. Istrate, and C. Munteanu, "Controlling and monitoring of welding parameters for micro-alloyed steel pipes produced by high frequency electric welding," Advanced Materials Research, vol. 1033-1036, pp. 464-469, 2014.

[10] J. G. Williams, "Advance in steels for high strength ERW linepipe application in Australia," Materials Forum, vol. 31, pp. 1-10, 2007.

[11] S. Toyoda, S. Goto, T. Okabe et al., "Mechanical properties of newly developed API X80 grade HFW linepipe for long-term exposure at elevated temperature," in Proceedings of the International Conference on Offshore Mechanics and Arctic Engineering, vol. 5, pp. 1-7, San Francisco, CA, USA, 2014.

[12] B. Pinheiro, I. Pasqualino, and S. Cunha, "Fatigue life assessment of damaged pipelines under cyclic internal pressure: pipelines with longitudinal and transverse plain dents," International Journal of Fatigue, vol. 68, pp. 38-47, 2014.

[13] J. X. Zhao, W. X. Chen, K. Chevil et al., "Effect of pressure sampling methods on pipeline integrity analysis," Journal of Pipeline Systems Engineering and Practice, vol. 8, no. 4, article 04017016, 2017.

[14] B. C. Pinheiro and I. P. Pasqualino, "Fatigue analysis of damaged steel pipelines under cyclic internal pressure," International Journal of Fatigue, vol. 31, no. 5, pp. 962-973, 2009.

[15] J. C. R. Pereira, A. M. P. de Jesus, A. A. Fernandes, and G. Varelis, "Monotonic, low-cycle fatigue, and ultralow-cycle fatigue behaviors of the X52, X60, and X65 piping steel grades," Journal of Pressure Vessel Technology, vol. 138, no. 3, article 031403, 2016.

[16] M. A. Neves Beltrão, E. M. Castrodeza, and F. L. Bastian, "Fatigue crack propagation in API 5L X-70 pipeline steel longitudinal welded joints under constant and variable amplitudes," Fatigue and Fracture of Engineering Materials and Structures, vol. 34, no. 5, pp. 321-328, 2011.

[17] O. Fatoba and R. Akid, "Low cycle fatigue behaviour of API 5L X65 pipeline steel at room temperature," Procedia Engineering, vol. 74, pp. 279-286, 2014.

[18] C. Taylor, S. Das, L. Collins, and M. Rashid, "Fatigue crack growth at electrical resistance welding seam of API 5L X-70 steel line pipe at varied orientations," Journal of Offshore Mechanics and Arctic Engineering, vol. 139, no. 3, article 031401, 2017.

[19] G. L. Zhang, J. H. Luo, X. W. Zhao, H. Zhang, L. Zhang, and Y. Zhang, "Research on the fatigue character of ERW pipe welded seam and fatigue life assessment method," in Proceedings of the Biennial International Pipeline Conference, vol. 1, pp. 365-373, Calgary, Canada, October 2010.

[20] P. Chowdhury and H. Sehitoglu, "Mechanisms of fatigue crack growth-a critical digest of theoretical developments," Fatigue and Fracture Engineering Materials and Structure, vol. 39, no. 6, pp. 652-674, 2016.

[21] L. Poberezhnyi, P. Maruschak, O. Prentkovskis, I. Danyliuk, T. Pyrig, and J. Brezinová, "Fatigue and failure of steel of offshore gas pipeline after the laying operation," Archives of Civil and Mechanical Engineering, vol. 16, no. 3, pp. 524-536, 2016.

[22] Z.-P. Zhao, G.-Y. Qiao, G.-P. Li, W.-W. Yang, B. Liao, and F.-R. Xiao, "Fatigue properties of ferrite/bainite dual-phase X80 pipeline steel welded joints," Science and Technology of Welding and Joining, vol. 22, no. 3, pp. 217-226, 2016. 
[23] Y. J. Kim, J. K. Kwon, H. J. Lee, W. K. Jang, J. K. Choi, and S. S. Kim, "Effect of microstructure on fatigue crack propagation and S-N fatigue behaviors of TMCP steels with yield strengths of approximately $450 \mathrm{MPa}, "$ Metallurgical and Materials Transactions A, vol. 42, no. 4, pp. 986-999, 2011.

[24] A. Toumpis, A. Galloway, L. Molter, and H. Polezhayeva, "Systematic investigation of the fatigue performance of a friction stir welded low alloy steel," Materials and Design, vol. 80, pp. 116-128, 2015.

[25] P. Maruschak, L. Poberezhny, and T. Pyrig, "Fatigue and brittle fracture of carbon steel of gas and oil pipelines," Transport, vol. 28, no. 3, pp. 270-275, 2013.

[26] D.-H. Jung, J.-K. Kwon, N.-S. Woo, Y.-J. Kim, M. Goto, and $\mathrm{S}$. Kim, "S-N fatigue and fatigue crack propagation behaviors of X80 steel at room and low temperatures," Metallurgical and Materials Transactions A, vol. 45, no. 2, pp. 654-662, 2014.

[27] K. Miková, S. Bagherifard, O. Bokuvka, M. Guagliano, and L. Trško, "Fatigue behavior of X70 microalloyed steel after severe shot peening," International Journal of Fatigue, vol. 55, pp. 33-42, 2013.

[28] Y. Zhong, Y. Shan, F. Xiao, and K. Yang, "Effect of toughness on low cycle fatigue behavior of pipeline steels," Materials Letters, vol. 59, no. 14-15, pp. 1780-1784, 2005.

[29] F. R. Xiao, X. L. Han, Y. M. Liu, G. P. Lu, and B. Liao, "Effects of induction heat treatment on austenitic transformation, microstructure and mechanical properties of pipeline steels," Materials Science Forum, vol. 773-774, pp. 749-757, 2014.

[30] Y. M. Liu, G. P. Lu, Y. B. Cao et al., "Effects of heating rate and holding time on microstructure and mechanical properties of X70 steel," Heat Treatment of Metals, vol. 37, no. 2, pp. 49-53, 2012, in Chinese.

[31] H. Mughrabi, "Cyclic slip irreversibilities and the evolution of fatigue damage," Metallurgical and Materials Transactions B, vol. 40, no. 4, pp. 431-453, 2009.

[32] Q. Q. Jiang, C. Q. Sun, X. L. Liu, and Y. S. Hong, "Very-highcycle fatigue behavior of a structural steel with and without induced surface defects," International Journal of Fatigue, vol. 93, pp. 352-362, 2016.

[33] Q. Jin, Z. Y. Sun, and W. N. Guo, "Experimental and finite element study on the fatigue growth of a semi-elliptical surface crack in a X80 pipeline steel specimen," Applied Mechanics and Materials, vol. 580-583, pp. 3026-3029, 2014.

[34] T. Vuherer, L. Milović, and V. Gliha, "Behaviour of small cracks during their propagation from Vickers indentations in coarse-grain steel: an experimental investigation," International Journal of Fatigue, vol. 33, no. 12, pp. 1505-1513, 2011. 


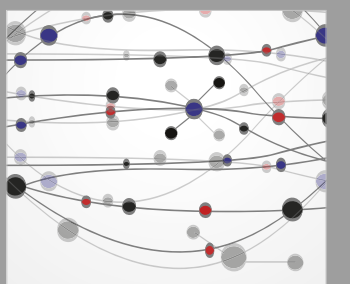

The Scientific World Journal
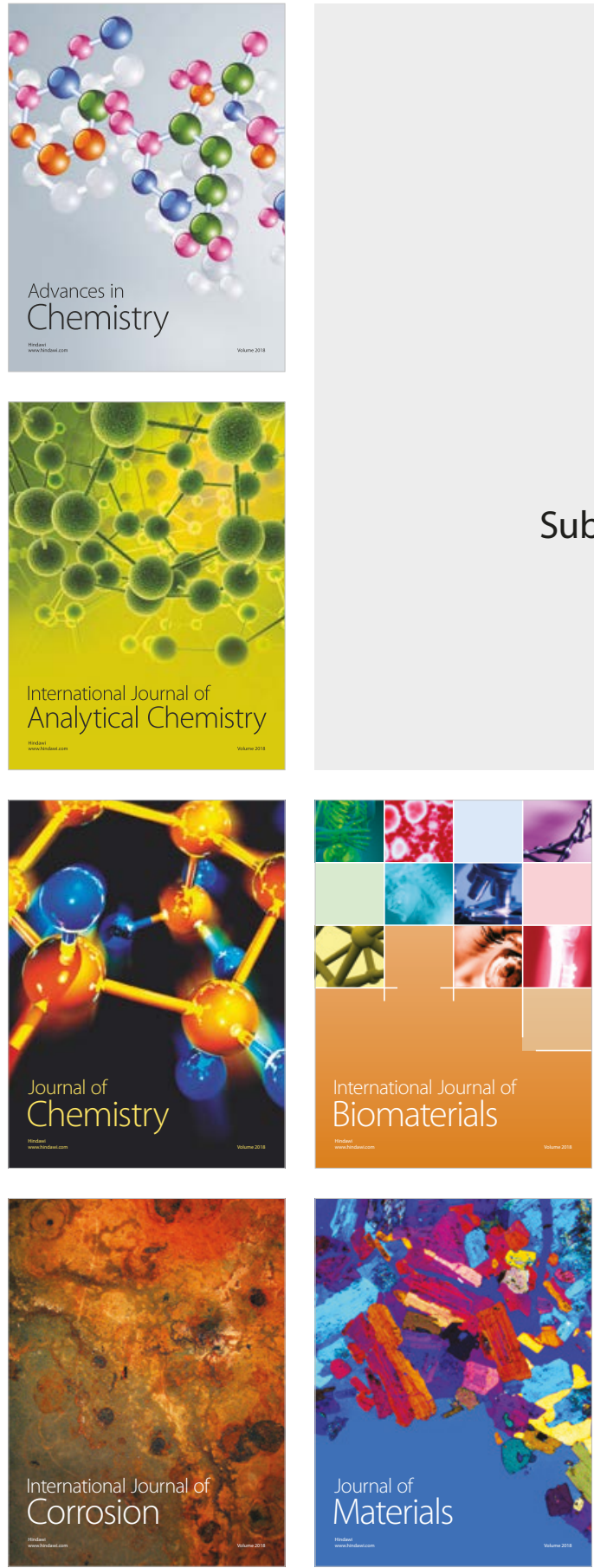

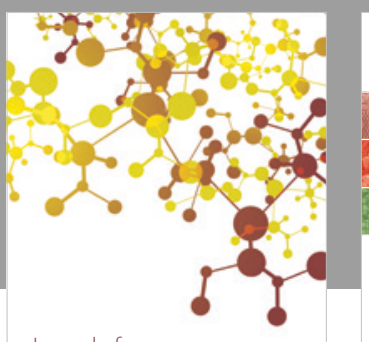

Journal of

Applied Chemistry
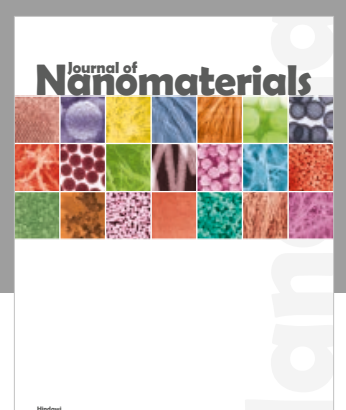

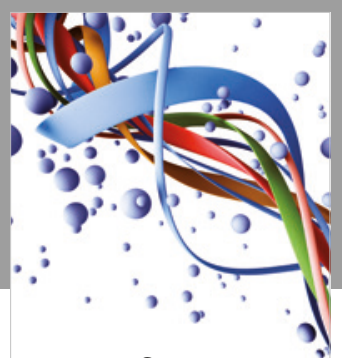

Scientifica

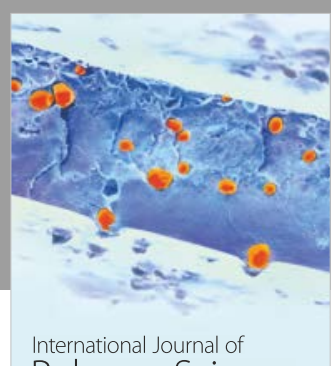

Polymer Science

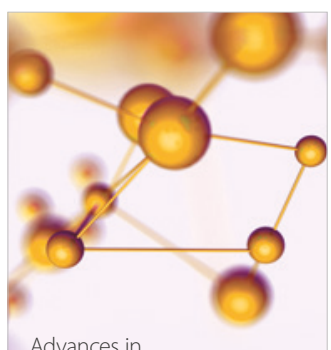

Physical Chemistry
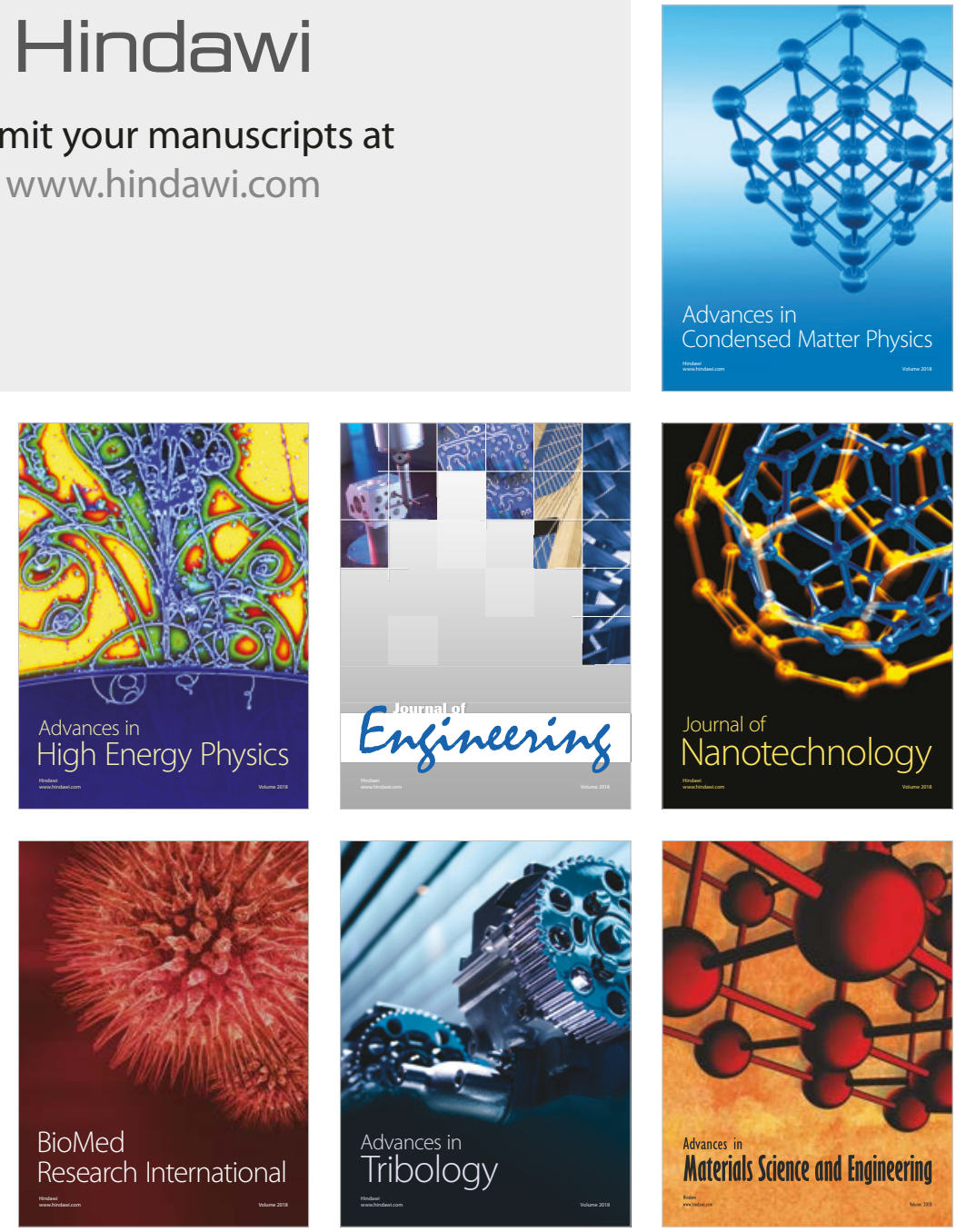